\title{
Multiple methods beyond triangulation: Collage as a methodological framework in geography
}

\section{Cordelia Freeman}

Department of Geography, University of Exeter, Exeter, UK

Geography Department, Amory Building, Rennes Drive, The University of Exeter, Exeter EX4 4RJ. c.freeman@exeter.ac.uk

orcid: 0000-0003-2723-8791

Triangulation is increasingly being seen as a concept that has lost clarity and become too broad to be of use. A new language is required to explain how and why researchers bring together multiple perspectives to study phenomena. By drawing on my own research experiences I propose 'collage' as a framework for using multiple methods in geography. This framework differs from triangulation in two important ways: firstly, it brings multiple methods together to elucidate a broad research area rather than a precise one, and secondly, it allows for greater spontaneity and the shifting of the frame of research. This paper explains how multiple methods can be used to gather fragments of knowledge on a topic that, when pieced together, can create a more complex understanding of the wider research area. A focus on this process emphasizes the role of the researcher in putting the pieces together.

Keywords: collage; bricolage; triangulation; research methods; multiple methods 


\section{Introduction}

The term 'collage' usually conjures up childhood memories of scouring magazines and newspapers, cutting out pictures and text, and gluing them onto a fresh sheet of paper. In this paper I draw on this artistic practice to propose a framework for conducting multiple methods research. ${ }^{1}$ Collage as a methodological framework for multiple methods research entails using different methods for their ability to elucidate understanding of a part of the wider research area rather than using different methods to each converge on the same specific topic. I developed this during my own research whereby, because I was using multiple methods, I presumed I was 'doing triangulation' (Freeman 2017a). I was studying the history of violence on the Chile-Peru border between 1925 and 2015 and found I needed to work in a spontaneous way to be open to a wide range of sources and information that I came upon during fieldwork. My research area was very broad and flexible as I incorporated new topics as I came upon them and this did not seem compatible with triangulation at all. I was not rigorously using methods that were all studying a precise, pre-defined, and fixed research question. My search for a way to explain what I was doing led me to develop collage as a methodological framework.

\section{A Case for Collage}

Triangulation is falling out of favour as a way to conceptualize multiple methods research.

Critiques of triangulation are not new. Almost three decades ago, Blaikie (1991) called for a 'moratorium' on the use of the concept of triangulation. He contended that new

\footnotetext{
${ }^{1}$ The terms 'mixed methods' and 'multiple methods' often refer to combining qualitative with quantitative approaches (Philip 1998). However, research combining methods that are all qualitative in nature are commonplace in human geography and lauded for their ability to create depth and complexity (Barbour 2006; Hemming 2008). In this paper I will use 'multiple methods' to refer to the combination of qualitative methods.
} 
labels for multiple methods research were necessary in order to be more exact about how multiple methods are used. More recently, the editors of the Journal of Mixed Methods Research published an editorial dissociating the journal from triangulation (Fetters and Molina-Azorin 2017). They argued that triangulation no longer best serves the field of mixed methods research and stressed the need for an alternative language. This paper responds to the calls by Blaikie and Fetters and Molina-Azorin by developing collage as an alternative framework to conduct multiple methods research. I agree with them to argue that it is necessary to be more specific and precise in how we as academics differentiate between types of multiple methods research. My aim is that this paper will prompt such discussions about methodological innovation to re-evaluate triangulation and consider how and why we combine methods in geography. Multiple methods research is commonplace in geographical research yet detailed discussion of how it works is an 'absent presence' (McKendrick 2009, 133). McKendrick (ibid., 133) states that multimethod research 'is widely practiced, but is not openly discussed in methodological debates' in geography. As Hitchings and Latham (2020) pointed out in their recent review of qualitative methods for Progress in Human Geography, in-depth discussions of how we analyse and evaluate data remain overlooked in the discipline. This paper seeks to rectify this gap.

One strategy has been to adapt triangulation to break it free from its rigid origins. Ley $(2015,227)$, for example, advocates 'a messier strategy of triangulation, building off several methodological positions, rather than a purer model that favours a single methodological base point'. But triangulation does not have to be merely adapted or broadened. We can put triangulation aside in favour of a new language. This paper proposes collage as a new framework that moves beyond triangulation and better accounts 
for the messiness of multiple methods research in geography. I posit two key ways that collage differs from triangulation:

1. Triangulation combines multiple methods to study a precise topic whereas collage combines multiple methods to research a broad research area

2. Triangulation works from a pre-decided set of multiple methods whereas collage is more open to spontaneity and the shifting of the frame of research

Collage in the English language developed from the French coller meaning 'to stick', or 'a glued work'. As an artistic practice it involves taking pre-existing materials and media and arranging them in a new way. It was popularized by Pablo Picasso and Georges Braque who reacted against formalist art in the pursuit of artistic innovation. For Picasso, in collage

This displaced object has entered a universe for which it was not made and where it retains, in a measure, its strangeness. And this strangeness was what we wanted to make people think about because we were quite aware that the world was becoming very strange and not exactly reassuring. (cited in Brockelman 2001, 117-118)

For Picasso this is more than aesthetics, he was questioning the very meaning of representation. Artistic collage incorporates shards or fragments to move toward a new or alternative, potentially even radically different meaning (Davis 2008). It is in this way that the intended meanings behind the original materials or objects included in the collage can purposefully or inadvertently change the meaning of representation. The term collage has been taken up by cultural geographers to discuss arts-based approaches and visual techniques (see Hawkins 2014; Rose 2016; Tolia-Kelly 2013; Tuan 2004) and by researchers who use the literal cutting and pasting of images and texts into a new form as an exploratory/analytical approach as well as a form of representation (Butler-Kisber 2008). However, collage in this paper differs from those approaches as I use it in a 
metaphorical sense, not a literal one, as a framework to analyse multiple methods research on a broad and potentially shifting research area.

I underpin my explanation of collage through the example of my own research on violence on the Chile-Peru border and I will thread my own research experiences through the paper. I show how collage allows the researcher to use multiple methods, not to neatly compare theoretical or methodological perspectives, but to work through the rich and messy patchwork of fragments that arise from research and to consider how these parts interrelate. When conducting my doctoral research I needed a way to think about how different sources were giving me different perspectives on the border history of ChilePeru which seemed incompatible with triangulation. I also found that my research strategy changed and I needed a framework that allowed me to change the focus of my research and bring in new sources and methods in a more ad-hoc away than triangulation allows for. Collage became a strategy to bring all the information I collected together in a productive and epistemologically open manner and to provoke me to consider how I chose to piece together the information I collected. This paper will next explain the two ways that collage differs from triangulation: firstly, the ability to study a broad research area rather than a precise one, and secondly, the greater potential for spontaneity and the shifting of the frame of research. These are followed by a discussion of what to do with the fragments of information collected through the research. 


\section{Multiple methods for a broad research area}

The first way in which collage can be more appropriate for some forms of multiple methods research than triangulation is that in triangulation, multiple methods are used to converge on one specific topic (what Denzin (1970) calls 'the same phenomenon'; figure one). However, with collage, multiple methods are used because they each provide different fragments of information that, when pieced together, help to explain a broad research area. In this section I will provide a more in-depth critique of triangulation and explain how collage as a framework addresses this critique. I will show how, through my own research on violence on the Chile-Peru border, collage allowed me to gather and analyse diverse information on an expansive topic and period.

The etymology of 'triangulation' leads us back to geodesy and the surveying technique whereby fixed points are measured in order to calculate a line or a point. Under this literal definition, triangulation is a technique using two known locations to pinpoint an unknown one. These geodetic origins are evident in definitions such as that triangulation 'refers to the cross-referencing of one piece of evidence with another in order to better determine what the actual position is' (Kesby, Kindon and Pain 2005, 145). Triangulation as a way to describe the use of two or more methods in the social sciences was championed by Norman Denzin (1970) and Donald Campbell and his colleagues (Campbell and Fiske 1959). It became a way to use multiple methods or multiple sources to enrich understanding of a research question (Valentine 2005), often relying on 'convergence' to ensure robustness (Hesse-Biber 2010). Triangulation covers a wide variety of techniques, not for the pursuit of 'objective' truth necessarily but to add rigour to analysis (Fielding and Fielding 1986). 
Since its inception, triangulation has expanded so greatly in meaning that it can encompass a variety of approaches. As Thurmond (2001) has set out in her literature review, triangulation can mean the combining of data sources, investigators, methods, theories or data-analysis. This has not uniformly been seen as a strength. Fetters and Molina-Azorin $(2017,7)$ claimed that 'triangulation has a very broad range of meanings, so many that it borders on meaningless' while others have argued that when any combination of research methods can be called triangulation, then triangulation as originally defined becomes diminished (Breitmayer, Ayres and Knafl 1993). It is these critiques that led to researchers calling for the term to be retired (Blaikie 1991, Fetters and Molina-Azorin 2017).

Nevertheless, triangulation is still commonly used in geographical research. The term can be found in the indexes of many human geography methods textbooks (see Clifford, Cope, Gillespie, and French 2016; Flowerdew and Martin 2005) yet when readers follow the page numbers substantial explanations and practical guides are rarely found. David Silverman's (2013) Doing Qualitative Research: A Practical Handbook even directs readers to 'credibility' if they search for 'triangulation' in the index. Students in particular are encouraged to combine methods (most notably in undergraduate dissertations) and the benefits of triangulation are widely extolled. Triangulation is often upheld as best practice in research with Norman Denzin (1989, 13, 25, my emphasis) stressing that social scientists 'must learn to employ multiple methods in the analysis of the same empirical events... Because each method reveals different aspects of empirical reality'. It is too often seen uncritically as a catch-all way 'to fill empirical and theoretical gaps, add needed context, incorporate multiple truths, triangulate different sources of data 
off of each other, and produce the generalizable and the particular' (Warshawsky 2014, 161). Such claims hide the many difficulties of achieving them.

As traditionally conceived, triangulation necessitates choosing a precise point and examining it from different perspectives whether these be of methods, investigators, theories, or data sources (Denzin 1989). What triangulation cannot do, therefore, is accommodate a broad frame of research. This is where collage offers an alternative. As a methodological framework, collage allows for the bringing together of multiple methods precisely because each one elucidates understanding of a wider research area. For a researcher using collage, there are no constraints on what the methods or sources collected and analysed might be. This will be dependent on the research area, what is available to the researcher, and what the skill set of the researcher or research team is. This may cover qualitative approaches such as interviews, participant observation, visual analysis and so on, and researchers may want to experiment with including quantitative data too. The aim is that the methods and sources chosen are each providing a different perspective on the borader research area. To explain this in more detail, I will show how collage works in practice through my own research.

I developed collage as a methodological framework as I grappled with studying a time frame that spanned from the 1920s until 2015 (Freeman 2015). My research was about the history of violence on the border between Chile and Peru with a focus on the Chilean border city of Arica. Historical geography methods could only account for half of the unknown; other approaches would need to be employed to understand the city in more recent times. The period of study from the 1920s to the 1950 s necessitated archival research so I went to numerous archives in four countries in search of glimpses into these 
decades. I looked at declassified CIA files, municipal planning documents, photographs, newspapers, and personal diaries amongst others. I was interpreting 'violence' broadly and these sources encompassed a range of issues such as military violence, diplomacy, racism, and misogyny. I was able to piece together one understanding of the border historically but not for more recent decades.

When I was considering Arica from the 1960s, a different research method became available to me; oral histories. I had the luxury of talking to people who lived on the border at the time I was interested in. Oral histories come with methodological challenges but they were crucial to help me understand how inhabitants of Arica construct their own past and how violence has been inflicted and resisted (Freeman 2019). Then for present day events I was able to conduct in-depth semi-structured interviews with a wide range of participants. This did not mean that I stopped using archival methods; newspapers, government documents, and other files were still vital, but I was able to diversify the methods I was using to complexify my picture of violence on the Chile-Peru border. Oral histories and interviews also offered me something that the archives could not: dialogue and the opportunity to direct questions to participants specifically about my research interests. This did not mean I was studying the same phenomena through different research methods; each method was adding to my understanding of my broad research area.

I then decided to add even more perspectives. By delving into the online world and researching YouTube, Facebook, and Twitter, I was able to complicate the people and places I was studying in ever more interesting ways with up-to-the-minute information and a more diverse set of voices. I incorporated this method as a geopolitical 
event that was relevant to my research, the maritime border dispute on the Chile-Peru border that was heard at the International Court of Justice, suddenly generated a significant amount of online data. Through social media analysis I was able to access the comments of far more people than I could have interviewed. The nature of the data collected was also different, scouring found information rather than asking people questions. This made the process more similar to dealing with information from historical archives. Through social media analysis I was collating my own archive of online materials, taking seriously memes and comments left under videos. I was collecting the fragments of information about the bigger story of violence on the Chile-Peru border through these multiple methods. Figure two illustrates how these different methods I used each helped me understand a different aspect of my broad research area. These methods were specific to the place and themes I was studying and other researchers using collage will use a different combination of multiple methods.

My collage approach allowed me to study a very broad research area that encompassed historical and contemporary legal disputes, fiscal initiatives, abortion travel, HIV transmission, and more. Whereas triangulation would have been appropriate to study one of these topics alone from a variety of methods, I was using each method to shed light on a different part of my broad research area of violence on the Chile-Peru border. The limits or frame of the research area will be planned in the process of the research design and some frames will encompass very broad areas whereas others will be less broad. A unique strength of collage as a way to conduct multiple methods research is its ability to cover such broad research areas so researchers studying very precise topics may find triangulation more suitable. However, defining what will be included in the study frame does not only happen before the research begins. As I found in my own 
research, the frame of research needed to be adapted as I progressed with my research and the spontaneity needed for this was also something that triangulation is not well suited for. The following section explains this second differentiation of collage from triangulation.

\section{An openness to spontaneity}

Proponents of triangulation argue that for it to be robust, the methods and research topic should be decided upon before the research begins, with a 'clear rationale' (Hastings 2010, Fetters and Molina-Azorin 2017). Triangulation begins with a precise frame from the outset and the methods employed are designed to provide a set of results within that frame. In the case of my own research, I certainly had hopes and plans for such clarity but the unpredictability of fieldwork meant this was far from the reality. I therefore needed to consider how multiple methods research could account for the introduction of alternative methods and the adaptation of the frame of my research. As I began conducting research on fieldwork in the United States and Chile, I realised that much of my prior reading and research was irrelevant or outdated. Starting the research in situ opened my eyes to events and phenomena that I had never considered. I needed to shift my frame of research in an ad hoc way which entailed changing the title, aims, and methods of my project as the research unfolded. Collage allowed me to conceptualize this as it showed how the frame can be expanded or contracted, and new areas can be brought into the frame, while others are removed. Just as a cartographer decides what is to be included and what is to be excluded from the frame of a map, the collage researcher draws 
a boundary to demarcate what the focus of the research is. The frame may be redrawn or shifted through the research process and this is a highly subjective process. Spontaneity and the ability to adapt the frame more adequately reflects the construction of knowledge by the researcher and the improvisation that is so necessary in research, particularly when conducting fieldwork.

My search for a way to be open to spontaneity led me to 'bricolage'. Bricolage is most commonly found in the postmodern inflected parts of cultural studies and art theory. There it is understood as subverting meaning and context through the reworking of traditional objects, often using found items in new and diverse ways (Hebdige 1981). However, the term remains significant beyond these realms. The term bricoleur originates from the French for 'handy(wo)man' or 'tinker'; someone who makes use of the tools they have available to them. The bricolage is the object they produce. Claude Lévi-Strauss brought the term bricolage into mainstream social theory in his 1962 book The Savage Mind. Lévi-Strauss' formation of bricolage is limiting in that it posits that the bricoleur does not create new knowledge but must instead "make do with "whatever is at hand" (1968, 17). Lévi-Strauss defined the bricoleur as an 'amateur', someone who 'uses devious means compared to those of a craftsman' [sic] $(1966,17)$. Since then the term has been picked up and developed by theorists such as Michel de Certeau (2011), Jacques Derrida (1967) and Clifford Geertz (1988).

An important change occurred when Denzin and Lincoln (1994) repurposed the idea of bricolage and replaced Lévi-Strauss' 'amateur bricoleur' with an 'expert bricoleur'. This expert was still making use of whatever was at hand but was doing so with purpose and within a context. Denzin and Lincoln shifted bricolage as something to 
be studied to a method of studying. Bricolage as a social science research method therefore materialized. The concept is defined in the 1994 introduction to The Sage Handbook of Qualitative Research as 'the combination of multiple methods, empirical materials, perspectives and observers in a single study', that adds 'rigor, breadth, and depth to any investigation' (Denzin and Lincoln 1994, 2). Denzin and Lincoln (2000) noted that the concept of bricolage is manifold and elastic and indeed the term morphs between their 1994, 2000, and 2005 editions of the introduction to the handbook. The three editions show a clear historiography of bricolage as method and, thanks to Denzin and Lincoln, bricolage had entered methods discourse.

Denzin and Lincoln's bricolage has been criticized, most notably by Hammersley (1999) who claimed that their combination of paradigms led to theoretical weakness. Nevertheless, it was taken up emphatically by the North American Professor of Education, Joe L. Kincheloe, who did much to ground the concept of bricolage. Kincheloe (2001) extended Denzin and Lincoln's idea of the bricoleur as an 'expert' and stressed the rigorous nature of such research as researchers are not 'chained' to assumptions but can compare differing methods, epistemologies, and social theoretical assumptions. The expertise and novel perspective that the bricoleur brings can highlight the blind spots that come with working within one discipline and allows the researcher to 'peer through a conceptual window to a new world of research and knowledge production' (Kincheloe $2005,323)$. Johnson $(2011,37)$ argued that '[m]any characteristics of the bricoleur are important if one is going to conduct mixed research successfully'. These characteristics include creativity, openness, spontaneity, and being able to use existing methods in new ways. Bricolage gives agency to the researcher to question pre-existing research methodologies and to adapt them to better suit the needs of their research. Before we 
begin our research we cannot always know where the frame will end, which methods will fill in which parts of our wider picture, and where the unseen areas will be. Therefore, the key difference between triangulation and bricolage is that where triangulation draws upon a set of pre-defined, complementary methods, bricolage allows for Lévi-Strauss' makedo-and-mend mentality; creating and moulding tools where necessary with little care for the neatness of structured methods.

It is here that bricolage informs my proposed framework of collage. Indeed, Denzin and Lincoln $(2005,6)$, the key proponents of bricolage, themselves used the term collage in their discussion of qualitative research stating that the bricoleur produces ' $\mathrm{a}$ complex, dense, reflexive collage-like creation'. Yet, I propose collage instead of repurposing bricolage because Kincheloe's development of bricolage places interdisciplinarity at its centre. Bricolage, like triangulation, has become a broad and fuzzy term whereas what is necessary is a clearer language of conducting multiple methods research in geography beyond the constraints of triangulation. Bricolage is an important approach to research in the social sciences and has been unjustly undertheorized within geography. However, collage, inspired by bricolage, provides a clean slate to conceptualize methodologies.

My initial 'survey' of the field led me to believe that triangulation would be the most sensible approach to conduct my research. But being in the field showed me that I needed to be more spontaneous and open to new information and sources that would not neatly fit into pre-defined categories with triangulation. For example, my research on violence on the Chile-Peru border ended up examining reproductive rights as biopolitical violence (Freeman 2017b; Calkin and Freeman 2018). Before I began fieldwork I had 
never imagined that I would be studying abortion. During a chance conversation I learnt about women crossing the border from Chile to Peru for abortions and I decided to adapt my research topic and methods to include this phenomenon and expand how I was using the term 'violence'. I was also engaging with wider literatures than I had encountered in my British university education and my research agenda was being shaped by the Latin American decolonial and feminist theories I was reading. This adaptation would not have been in the spirit of triangulation. Using collage as a methodological framework, I pieced together fragments of information about women who travel from Chile to Peru in search of abortions from media reports, state statistics, and interviews with governmental and non-governmental healthcare workers, Church officials, and those directly involved. Collage differs from triangulation here because rather than setting out the methods I would use before conducting the research (as recommended for triangulation), it was an intuitive process whereby I adapted my approach depending on what information was available and who would discuss such a delicate topic with me. Until 2017, abortion was illegal in every single circumstance in Chile, making it a highly taboo and sensitive topic to research. The illegality and stigmatisation of abortion meant that it was necessary to take a gentle approach and gather the information that I could in such a strained environment. This was a sequential process where data collection informs future methods and approaches. Collage, inspired by bricolage, needs to maintain an air of spontaneity and 'tinkering' in order to be most effective and this spontaneity is crucial for feeling out ways to gather information, rather than collecting information based on a pre-decided set of methods.

Critics have argued that triangulation is only 'true' if the use of multiple methods is part of the study design from the outset (Fetters and Molina-Azorin 2017). This means 
that triangulation as traditionally conceived cannot account for the type of improvisation that is inescapable when conducting qualitative research in the field. As the research process develops it can become clear that an alternative method will need to be added to the methodology and so the option of flexibility must be built into the methodology. This is precisely what happened on my fieldwork when the utility of incorporating social media analysis became clear and when I needed to adapt my frame of research to include abortion travel. The need for a more flexible approach to methods is not a recent phenomenon. As C. Wright Mills (1959) insisted, methods should not be 'fixed'. Instead we need to understand the 'craft' involved. Through what he calls the 'craft attitude', Sanscartier (2018) argues that researchers can navigate the 'mess' that enters multiple methods research. Importantly here, Sanscartier's 'craft attitude' is designed to adapt to changing research contexts. This is particularly pertinent to research in the field where adaptability and the ability to change the research process in response to research experiences is unavoidable. Thus, when I adapted my project to include abortion travel, I was unknowingly adopting the craft attitude to adapt to this new area of research. The next step was to consider how to bring all these fragments of information together.

\section{Piecing the fragments together}

As the previous sections have shown, collage is a framework for conducting multiple methods research that is specifically useful for broad research areas and for shifting the frame of research during the research process. But collage as artistic practice comes from the piecing together of fragments so this section will explain how in collage research the varying fragments of information generated through multiple methods research are brought together. 
The question of what to with all the fragments that result from collage demands creativity from the researcher. Collage as an artistic practice relies on how the materials collected are arranged and displayed. Creative choices such as whether images are accompanied by text or not, whether the background is filled in, or whether blank spots are left, are all significant (Norris 2008). Collage as a methodological framework likewise necessitates a careful consideration of how the variety of information collected through research is presented. Indeed, it can be the overlaps and the blank areas that still remain that can provoke the most interesting critical reflections. For Butler-Kisber and Poldma (2010) the process of (literal, artistic) collage as inquiry is what helps researchers to make sense of their data, to synthesize it, and to further their analysis. For them, "[t]he resulting visual juxtapositions frequently reveal new connections and understandings that have previously remained tacit" (Butler-Kisber and Poldma 2010, 3). Davis and Butler-Kisber (1999) say that this collage process makes our results 'strange', perhaps showing us associations that we had not expected.

In my research, the fragments I gathered from all these methodological techniques allowed me to build up one detailed and nuanced picture of life on a violent border over a ninety-year history. As figure two showed, the methods I used provided a perspective on a different aspect of the research area rather than each honing in on one specific topic. While a truly complete picture or an objective reality will always be impossible to ascertain (Haraway 1991), the multiple methods I had used and the process of thinking about how they relate in my analysis meant that I had a richer understanding than I could have gained through one method alone. From an ontological standpoint, collage does not assume that there is a single reality. There is no 'absolute richness' that can be attained but we can understand our research areas in more complex ways. Different parts of the 
collage can reflect multiple realities and research itself is storytelling (Daft 1983). This highlights the role of the researcher. As Beverley Skeggs $(1997,27)$ has argued 'there is no such thing as a disinterested knower', and we should more openly acknowledge what the researcher's interests are.

Gray (2002) asks the reader to imagine being an ethnographic researcher studying music festivals. Through the research, she argues, the researcher will collect various 'scraps' of data such as photographs, flyers, interviews, and observations. It is up to the researcher to decide how they will arrange these scraps as the arrangement will alter the 'story' of what is being presented. Gray likens this to a kaleidoscope where rearrangement leads to changing patterns, shapes, and colours. What Gray's example shows us is the way in which there is not an objective truth to be uncovered, instead the researcher is framing a certain perspective. This anti-positivist approach allows us to understand how meaning is created and presented through the 'putting-together' of methods and data into a chosen frame. As Blaikie (1991, 120, emphasis in original) has argued, 'social reality is not some 'thing' that may be interpreted in different ways; it is those interpretations'. We as researchers are always piecing together a story or reality to tell.

Mapping out how all these methods can speak to one another does not necessarily mean them fitting together neatly. As Harriet Hawkins $(2014,59)$ has stated, 'If montage/collage are understood as compositional practices of bringing things together, we are also required to think about how they stay together or fall away, meaningfully, conceptually, formally and materially'. Piecing the methods together and making them speak to one another is an interpretive and intuitive process but one that embraces overlaps as well as these gaps or 'falling away' that Hawkins refers to. The researcher(s), 
with their knowledge of the research area gets a feel for how the fragments of research fit (messily and incompletely) together. It is the process of seeing how pieces of information interrelate that is so important in helping the researcher think through their analysis (Butler-Kisber and Poldma 2010).

As figure three shows, collage is never going to show a 'true' whole, instead there will be connections but there will also be gaps. In my own research there were elements of overlap. For example, when I was researching life in Arica under the Pinochet regime in the 1970s and 1980s, I was learning about the same events such as marches and parades from oral histories as well as from newspaper reports. However, other information was only available from one source. For instance, the Pinochet dictatorship was highly secretive and records were either never kept or destroyed when the transition to democracy came. This meant that certain pieces of information were only possible to ascertain from oral history interviews with those who were in the military at the time. This information is impossible to triangulate because there are no other methods or sources available. Therefore, the fragments of information from military sources were standalone pieces that added to the wider collage but did not overlap with other fragments. My research also threw up gaps. Some of these were 'known unknowns' where I was searching for information on a time period or event but was unable to locate any. I was also aware that I was not able to access all perspectives through my research. Many were starkly absent, most notably the voices of women and Indigenous communities in the online and historical archives. There are also 'unknown unknowns', to use Rumsfeldian speak. There will always be gaps but we might not know where or what they are. There is no 'true reality' to hold our collage against like a jigsaw puzzle box to see if it matches 
up. Research, especially spontaneous research in the field, will always be a grasping for richness rather than a neat piecing together of reality.

Collage forces us to think and work in a non-linear way (Butler-Kisber and Poldma 2010), in a jumble or a network; as with artistic collage the pieces are connected but sprawling. This celebrates juxtaposition and the interplay of fragments that may never have been pieced together through a different strategy (Vaughan 2005). Unexpected resonances and connections can stimulate discussion and learning and while triangulation works 'best' when multiple methods all reach the same conclusion, I argue that collage excels through its messiness. This methodological openness to messiness, however, is at odds with much academic writing. The writing process masks this messy cutting and pasting and re-working that actually goes into how we analyse our results in mixed methods research. We may feel pressured to hide our gaps and messiness to get through peer review and highlight our neatly packaged findings; discussing failures and inconsistencies in our data collection can feel like 'professional suicide' (Hitchings and Latham 2020). The smoothing out of the research process is common in most academic writing and this hides a lot of the realities of conducting research.

In my own research I certainly felt the pressure to present my findings in a neat and bounded way. I was submitting a $\mathrm{PhD}$ thesis that needed to adhere to certain conventions and appeal to the examiners. In retrospect this meant that I was not embracing the full potential of collage, to acknowledge gaps and the messiness of research. This meant that in my case, collage was a highly productive research framework but it did not feed through into my writing; something I hope to rectify in my future work. However, collage did produce interesting tensions, juxtapositions, and relationships 
between the different methods and fragments of information. This was central to me creating a 'hook' about violence on the Chile-Peru border that was able to span the ninety years of my research area. The appropriate manner to write from a collage methodology is therefore a challenge; whether to confine the messiness to the process of analysis, or to embrace it in the written form. For those favouring the former, collage is not the product as seen in arts-based approaches, it is only visible in the research process.

\section{Conclusion}

Multiple qualitative methods research is now commonplace in geographical research. For the past few decades triangulation has been held up as the go-to way to conceptualize the use of more than one method but it has come under sustained critique from across the social sciences. While triangulation has gone through various waves of development (Flick 2017) and some researchers have favoured broadening its definition out from its original iteration, others have called for the term to be abandoned (Fetters and MolinaAzorin 2017). It has become too broad and blurred to be of use and so we need a new language to conceptualize multiple methods research. I have proposed the framework of collage as one way to spark discussion about methodological debates in geography.

Collage is a methodological framework whereby multiple methods are used to gain a more complex understanding of a research area. This differs from triangulation in two main ways. Firstly, triangulation combines multiple methods to converge on a precise topic of research while collage is more appropriate for a broad research area where multiple methods are not used for convergence; instead, each one provides a glimpse into one part of the broader research area. Secondly, triangulation should have a 'clear rationale' from the outset while collage is much more open to spontaneity and the shifting 
of the frame of research. Collage as a methodological framework developed from my own experience of research where I was conducting multiple methods research but found explanations of triangulation limiting. As I conducted fieldwork, I found that I was not researching a precise topic through multiple methods; each method was telling me something different so they could not be crosschecked for validity or convergence. Moreover, due to all the unknowns of fieldwork I needed a framework that would allow me to incorporate new topics and methods as the research progressed rather than staying fixed to a pre-determined approach. For these reasons I developed collage as a way to explain my methodological approach.

Collecting information in a spontaneous and open way is one thing, but working out what to do with a diverse set of fragments of information is another. In my research I had generated pieces of information from historical and contemporary archival research, oral histories, contemporary interviews, social media analysis, and more. Collage involves celebrating these diverse fragments brought together in the research and the edges, messiness, and spaces in-between the fragments which are just as important as when the patches fit together neatly. Noting what certain methods cannot tell you can be as interesting as what they can. Such questioning nudges the researcher to consider how they want to arrange the information to tell a particular 'story' (Gray 2002) and what 'messy' research looks like in academic writing.

Collage as a methodological framework in geography is not appropriate for all geographical research but it does offer a new language for those who use multiple methods but are uncomfortable with triangulation. It is crucial that we as geographers join 
the discussions taking place in the wider social sciences about how we want to think about and talk about multiple methods research.

\section{Acknowledgements}

Many thanks to Nick Clare, Jake Hodder, Steve Legg, and David Beckingham for their very helpful comments on earlier drafts of this paper as well as the useful feedback from the anonymous reviewers. Any errors remain my own.

\section{Funding}

This work was supported by the University of Nottingham School of Geography and the Developing Areas Research Group (of the RGS-IBG) travel prize.

\section{Disclosure statement}

No potential conflict of interest was reported by the author. 


\section{References:}

Barbour, R. 2006. "Mixing qualitative methods: Quality assurance or qualitative quagmire.” In Mixed Methods, edited by A. Bryman, 229-241. London: Sage.

Blaikie, N. W. 1991. "A critique of the use of triangulation in social research." Quality and Quantity 25 (2): 115-136. doi:10.1007/BF00145701.

Breitmayer, B. J., L. Ayres and K. A. Knafl. 1993. "Triangulation in qualitative research: Evaluation of completeness and confirmation purposes." Image: The Journal of Nursing Scholarship 25 (3): 237-243. doi: 10.1111/j.15475069.1993.tb00788.x.

Brockelman, T. P. 2001. The frame and the mirror: On collage and the postmodern. Evanston, IL: Northwestern University Press.

Butler-Kisber, L. 2008. “Collage as inquiry.” In Handbook of the Arts in Qualitative Research, edited by J. G. Knowles and A. L. Cole, 265-276. Thousand Oaks, CA: Sage.

Butler-Kisber, L., and T. Poldma. 2010. "The power of visual approaches in qualitative inquiry: The use of collage making and concept mapping in experiential research.” Journal of Research Practice 6 (2): 1-16. doi:unavailable

Calkin, S., and C. Freeman. 2018. "Trails and Technology: Social and Cultural Geographies of Abortion Access.” Social \& Cultural Geography 20 (9), 13251332. Doi: $10.1080 / 14649365.2018 .1509114$

Campbell, D. T., and D. W. Fiske. 1959. "Convergent and discriminant validation by the multitrait-multimethod matrix." Psychological Bulletin 56 (2), 81-105. doi:10.1037/h0046016. 
Clifford, N., M. Cope, T. Gillespie and S. French, eds. 2016. Key Methods in Geography. $3^{\text {rd }}$ ed. London: Sage.

Daft, R. L. 1983. "Learning the craft of organizational research.” Academy of Management Review 8: 539-546. doi:10.5465/amr.1983.4284649.

Davis, D. 2008. “Collage inquiry: Creative and particular applications.” LEARNing Landscapes 2 (1): 245-265. doi:unavailable

Davis, D., and L. Butler-Kisber. 1999. “Arts-based representation in qualitative research: Collage as a contextualizing strategy." Paper presented to the Annual Meeting of the American Educational Research Association, Montreal, Canada. 20 April, 1999.

de Certeau, M. (1984) 2011. The Practice of Everyday Life: Volume One. Translated by S. Rendall. Berkeley, CA: University of California Press.

Denzin, N. 1970. The Research Act. Englewood Cliffs, NJ: Prentice Hall.

Denzin, N. 1989. The Research Act. $3^{\text {rd }}$ ed. Englewood Cliffs, NJ: Prentice Hall.

Denzin, N. K. And Y.S. Lincoln. 1994. "Introduction: The discipline and practice of qualitative research.” In The Sage Handbook of Qualitative Research. $1^{\text {st }}$ ed., edited by N. K. Denzin \& Y. S. Lincoln, 1-17. Thousand Oaks, CA: Sage.

Denzin, N. K. And Y.S. Lincoln. 2000. "Introduction: The discipline and practice of qualitative research.” In The Sage Handbook of Qualitative Research. $2^{\text {nd }}$ ed., edited by N. K. Denzin \& Y. S. Lincoln, 1-28. Thousand Oaks, CA: Sage.

Denzin, N. K. And Y.S. Lincoln. 2005. "Introduction: The discipline and practice of qualitative research.” In The Sage Handbook of Qualitative Research. $3^{\text {rd }}$ ed., edited by N. K. Denzin \& Y. S. Lincoln, 1-32. Thousand Oaks, CA: Sage.

Derrida, J. 1967. Writing and Difference. Translated by A. Bass. London: Routledge. 
Fetters, M. D. and J. F. Molina-Azorin. 2017. "The journal of mixed methods research starts a new decade: principles for bringing in the new and divesting of the old language of the field." Journal of Mixed Methods Research 11 (1), 3-10. doi: $10.1177 / 1558689816682092$.

Fielding, N. G. and J. L. Fielding. 1986. Linking Data. Newbury Park, CA: Sage.

Flick, U. 2017. “Triangulation in Data Collection.” In The Sage Handbook of Qualitative Data Collection, edited by U. Flick, 527-544. London: Sage. doi: https://dx.doi.org/10.4135/9781526416070.n34

Flowerdew, R. and D. Martin, eds. 2005. Methods in human geography: a guide for students doing a research project. $2^{\text {nd }}$ ed. London: Pearson Education.

Freeman, C. 2015. "Violence on the Chile-Peru border: Arica 1925-2015." Unpublished doctoral dissertation, University of Nottingham.

Freeman, C. 2017a. “Triangulating the Border.” In Your Human Geography Dissertation: Designing, Doing, Delivering, by K. Peters, 150-151. London: Sage.

Freeman, C. 2017b. "The crime of choice: Abortion border crossings from Chile to Peru." Gender, Place \& Culture 24 (6): 851-868. doi: 10.1080/0966369X.2017.1339020

Freeman, C. 2019. "Historical Everyday Geopolitics on the Chile-Peru Border." Bulletin of Latin American Research Early Online View doi: 10.1111/blar.13067

Geertz, C. 1988. Works and lives: The anthropologist as author. Stanford, CA: Stanford University Press.

Gray, A. 2002. Research practice for cultural studies: Ethnographic methods and lived cultures. London: Sage. 
Hammersley, M. 1999. "Not bricolage but boatbuilding: Exploring two metaphors for thinking about ethnography." Journal of Contemporary Ethnography 28 (6): 574-585. doi: 10.1177/089124199129023569.

Haraway, D. 1991. Simians, cyborgs, and women: the reinvention of nature. New York: Routledge.

Hastings, S. L. 2010. “Triangulation.” In Encyclopedia of Research Design, edited by N. J. Salkind, 1538-1540. Thousand Oaks, CA: Sage.

Hawkins, H. 2014. “Montage/collage: Art-making, place-making.” You Are Here: Journal of Creative Geographies 17 53-60. doi:unavailable

Hebdige, D. 1981. Subculture: The Meaning of Style. London: Routledge.

Hemming, P. J. 2008. "Mixing qualitative research methods in children's geographies." Area 40 (2): 152-162. doi:10.1111/j.1475-4762.2008.00798.x.

Hesse-Biber, S. N. 2010. Mixed methods research: merging theory with practice. New York: Guilford Press.

Hitchings, R., and A. Latham. 2020. "Qualitative methods III: On different ways of describing our work." Progress in Human Geography. Online First. doi:10.1177/0309132520901753

Johnson, R. B. 2011. "Do we need paradigms? A mixed methods perspective.” MidWestern Educational Researcher 24 (2): 31-40.

Kesby, M., S. Kindon and R. Pain. 2005. “'Participatory” approaches and diagramming techniques." In Methods in human geography: a guide for students doing a research project. $2^{\text {nd }}$ ed, edited by Flowerdew, R. and D. Martin, pp 144-166. London: Pearson Education. 
Kincheloe, J. L. 2001. "Describing the bricolage: Conceptualizing a new rigor in qualitative research." Qualitative Inquiry 7 (6): 679-692. doi: 10.1007/9789460913976_016.

Lévi-Strauss, C. 1966. The Savage Mind. Translated by G. Weidenfeld \& Nicolson Ltd. London: Weidenfeld and Nicolson.

Ley, D. 2005. "Places, People and Contexts." In Approaches to Human Geography: Philosophies, Theories, People and Practices. $2^{\text {nd }}$ ed, edited by Aitken, S. C. and G. Valentine, 224-30. London: Sage

McKendrick, J. H. 2009. "Mixed and Multiple Methods.” In International Encyclopedia of Human Geography, edited by Kitchin, R. and N. Thrift, pp. 128-133. London: Elsevier.

Norris, J. 2008. “Collage.” In The Sage Encyclopedia of Qualitative Research Methods, edited by Given, L. M., 94-97. London: Sage.

Philip, L. J. 1998. “Combining quantitative and qualitative approaches to social research in human geography_an impossible mixture?" Environment and Planning A 30 (2): 261-276. doi: 10.1068/a300261.

Rose, G. 2016. Visual methodologies. $4^{\text {th }}$ ed. London: Sage.

Sanscartier, M. D. 2018. “The Craft Attitude: Navigating Mess in Mixed Methods Research." Journal of Mixed Methods Research doi: doi.org/10.1177/1558689818816248.

Silverman, D. 2013. Doing Qualitative Research: A Practical Handbook. $4^{\text {th }}$ ed. London: Sage.

Skeggs, B. 1997. Formations of Class \& Gender: Becoming Respectable. London: Sage. 
Thurmond, V. A. 2001. "The point of triangulation." Journal of Nursing Scholarship 33 (3): 253-258. doi: 10.1111/j.1547-5069.2001.00253.x.

Tolia-Kelly, D. P. 2013. “The geographies of cultural geography III: Material geographies, vibrant matters and risking surface geographies." Progress in Human Geography 37 (1): 153-160. doi: 10.1177/0309132512439154.

Tuan, Y. F. 2004. "Cultural geography: Glances backward and forward." Annals of the Association of American Geographers 94 (4): 729-733. doi: 10.1111/j.14678306.2004.00427.x.

Vaughan, K. 2005. 'Pieced together: Collage as an artist's method for interdisciplinary research." International Journal of Qualitative Methods 4 (1): 27-52. doi: 10.1177/160940690500400103.

Warshawsky, D. 2014. "The potential for mixed methods: Results from the field in urban South Africa." The Professional Geographer 66 (1): 160-168. doi: 10.1080/00330124.2013.768141.

Wright Mills, C. 1959. The Sociological Imagination. New York: Oxford University Press 